\title{
New Strategies for Molecular Diversification of 2-[Aminoalkyl-(1H-1,2,3-triazol-1- yl)]-1,4-naphthoquinones Using Click Chemistry
}

\author{
Ronaldo N. de Oliveira, ${ }^{*, a}$ Mauro G. da Silva, ${ }^{a, b}$ Moara Targino da Silva, ${ }^{a}$ Valentina $N$. \\ Melo, ${ }^{a, b}$ Wagner O. Valença, ${ }^{a}$ Josinete Angela da Paz ${ }^{a}$ and Celso A. Camara ${ }^{a}$ \\ ${ }^{a}$ Laboratório de Síntese de Compostos Bioativos, Universidade Federal Rural de Pernambuco, \\ 52171-900 Recife-PE, Brazil \\ ${ }^{b}$ Departamento de Química Fundamental, Universidade Federal de Pernambuco, \\ 50740-540 Recife-PE, Brazil
}

\begin{abstract}
Click chemistry-based strategies for the synthesis of 2-amino-alkyl-1,2,3-triazole-1,4naphthoquinone derivatives make it possible to obtain desired products from 1,4-naphthoquinone (1,4-NQ), and bio-based lawsone, nor-lapachol and lapachol. The first route (Strategy A) starting from 1,4-NQ and amino alcohols, then 2-amino-alkyl-1,4-NQ alcohols, were tosylated. The azide ion displaced the tosylate group to afford 2-azide-alkyl-1,4-NQ, which was submitted to a copper-catalyzed azide alkyne cycloaddition (CuAAC) condition. The triazole-naphthoquinones were obtained in an overall yield of roughly 47\%. Another pathway (Strategy B) substituted bromo-alkyl-phthalimides using $\mathrm{NaN}_{3}$ as the nucleophile, sequential CuAAC and deprotection of phthalimide group with hydrazine producing amino-triazoles. The subsequent reaction with 1,4-NQ produced 2-amino-alkyl-1,2,3-triazole-1,4-NQ derivatives in an overall yield of 45-76\% in four steps. After we developed these two strategies, linear synthesis (Strategy A) was chosen to prepare 2-[(2-(1H-1,2,3-triazol-1-yl)ethylamino)]-3-(3-methylpropenyl)-1,4-naphthoquinones from lawsone with an overall yield of approximately $27 \%$ in six steps. On the other hand, convergent synthesis (Strategy B) was employed for the synthesis of 2-[(4-phenyl-1 H-1,2,3-triazol-1-yl)alkylamino)]-3-(3-methylbut-2-en-1-yl)-1,4-naphthoquinones from the reaction between 2-methoxylapachol with amino-triazoles with a global yield of about $21 \%$. These synthetic strategies might lead us to new opportunities to build small-molecule libraries for future biological exploration.
\end{abstract}

Keywords: click chemistry, amino-naphthoquinone, lapachol, nor-lapachol, 1,2,3-triazole

\section{Introduction}

The synthesis of New Chemical Entities (NCE) remains unaffected by changes in the focus of chemical science. ${ }^{1}$ A number of synthetic strategies have been developed recently to allow organic chemists to create a great variety of molecules. In order to access novel and diverse chemical libraries of compounds with potential biological activity the use of catalytic methods is prominent.

From a synthetic point of view, the Huisgen 1,3-dipolar cycloaddition reaction between organic azides and terminal alkynes has been a straightforward method to assemble a large number of molecules, especially since Sharpless and co-workers ${ }^{2}$ and Meldal and co-workers ${ }^{3}$ proposed the copper-catalyzed azide-alkyne cycloaddition ( $\mathrm{CuAAC}$ ).

*e-mail: ronaldo.noliveira@ufrpe.br
This protocol has permitted easy access to molecular diversity of 1,2,3-triazoles and encouraged synthetic chemists to design projects based on this scaffold. ${ }^{4-11}$ This reaction has provided the opportunity to synthesize molecules having new properties or biological activities, ${ }^{12,13}$ including anti-tuberculosis, ${ }^{14}$ antiviral, ${ }^{15}$ antitumoral, ${ }^{16-18}$ antifungal, ${ }^{19}$ antibiotic (e.g., tazobactam, see Figure 1a), ${ }^{20}$ among others, as can be found in the literature. ${ }^{21}$ Moreover, naphthoquinones moieties such as potent trypanocidal and leishmanicidal activities have been synthesized (Figure 1a). ${ }^{22-24}$

Since molecular hybridization between 1,4-naphthoquinone (1,4-NQ) and 1,2,3-triazole nucleus appeared as an important pharmacophore, ${ }^{25-29}$ this type of derivatives has become attractive as bioactive compounds. Various approaches have been focused on the connection between these derivatives. As a consequence, 
triazole-naphthoquinone hybrids have recently stood out in research on medicinal chemistry because of their structural diversity and biological properties. For instance, we recently synthesized triazole-naphthoquinone compounds, ${ }^{29}$ which after biological assays showed interesting activities against anti-T. cruzi, ${ }^{22}$ tumor cells ${ }^{17,30}$ and Leishmania sp. ${ }^{31}$ Furthermore, we published a study on the synthesis of a new class of compounds combining ultrasound and click chemistry, named amino-naphthoquinone-triazolephthalimide (ANT-Phthalimide); and ever since, we have been using this procedure in our laboratoty. ${ }^{32}$ To continue in this direction, our research group reported new building blocks with expressive medicinal properties; for example, 2-aminomethyl-naphthoquinone alkynes also reacted with azide-sugar to afford new ANT-sugars, which increased antitumor activity (Figure 1b). ${ }^{17}$ Another interesting example indicated amine substituted 1,4-naphthoquinones as potent GTPase inhibitors. ${ }^{33}$

In the present study, we report on the synthesis of novel 2-amino-alkyl-(1H-1,2,3-triazol-1-yl)-1,4naphthoquinones employing the copper-catalyzed Huisgen reaction between azide-alkyl-amino-1,4-naphthoquinones with terminal alkynes. These new structural diversity was prepared using the tactics of functionality inversion $\left(\mathrm{R}-\mathrm{N}_{3} \mid \mathrm{HC} \equiv \mathrm{C}-\mathrm{R}^{\prime}\right.$ or $\left.\mathrm{R}-\mathrm{C} \equiv \mathrm{CH} \mid \mathrm{N}_{3}-\mathrm{R}^{\prime}\right)$, functional variety from alkynes and branched alkyl chains (Figure 1b). In addition, we also report on the combination of bio-based origin scaffolds (lapachol and lawsone) with synthetic triazole-heterocyclic moiety.

\section{Results and Discussion}

Our investigation began with the reaction between naphthoquinone $\mathbf{1}(1,4-\mathrm{NQ})$ with aminoalcohols to furnish 2-hydroxyalkyl-amino-1,4-NQs 2-3 using $\mathrm{CH}_{3} \mathrm{CN}$ at room temperature for $3 \mathrm{~h}$ in yields of 73 and $67 \%$, respectively (Scheme 1). After that, the alcohol derivatives were tosylated using tosyl chloride and triethylamine in dichloromethane furnishing $\mathbf{4}$ and $\mathbf{5}$ in 68 and $81 \%$ yields, respectively. Then, the tosylated compounds 4-5 were carried out as substrates for the $\mathrm{S}_{\mathrm{N}} 2$ displacement reaction with $\mathrm{NaN}_{3}$ in DMSO to provide the azide $\mathbf{6}$ and $\mathbf{7}$ in almost quantitative yields. With the azide-1,4-NQs 6-7 in hands, the click protocol $\left(\mathrm{DMSO} / \mathrm{CuI} / \mathrm{Et}_{3} \mathrm{~N}\right.$ ) was employed using inert atmosphere at room temperature; thus, obtaining 1,2,3-triazole compounds 8a-d and 9a-d in good to excellent yields of 70-96\% under copper-catalyzed conditions (Table 1).

In fact, Strategy A (cf. Scheme 1) for the synthesis of 2-amino-alkyl-(1H-1,2,3-triazol-1-yl)-1,4-naphtho-

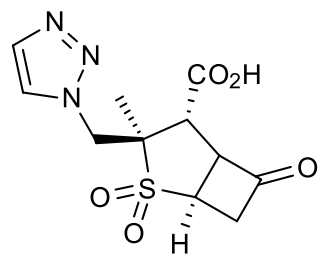

a)

Tazobactam<smiles>[R]c1cn(C2=CC(=O)c3ccccc3C2=O)nn1</smiles>

Triazol-1,4-naphthoquinone anti-T. cruzi (Ref. 22) antitumoral (Ref. 30) leishmanicidal (Ref. 31)<smiles>[R]C1C2=C(OC1([R])[R])c1ccccc1C(=O)C2=O</smiles>

ortho-Naphthoquinones (Refs. 22-24) $\mathrm{R}^{1} / \mathrm{R}^{2}=\mathrm{H}, \mathrm{CH}_{3}, \mathrm{CH}_{3}\left(\mathrm{CH}_{2}\right)_{7}$ $\mathrm{R}^{3}=\mathrm{H}, 1,2,3$-triazole
New Design for Structural Diversity of amino-naphthoquinone-triazole (ANT)

b)<smiles>[R]C1=C(NCc2cn([R])nn2)C(=O)c2ccccc2C1=O</smiles>

antitumor activity (Ref. 22) ANT-sugars

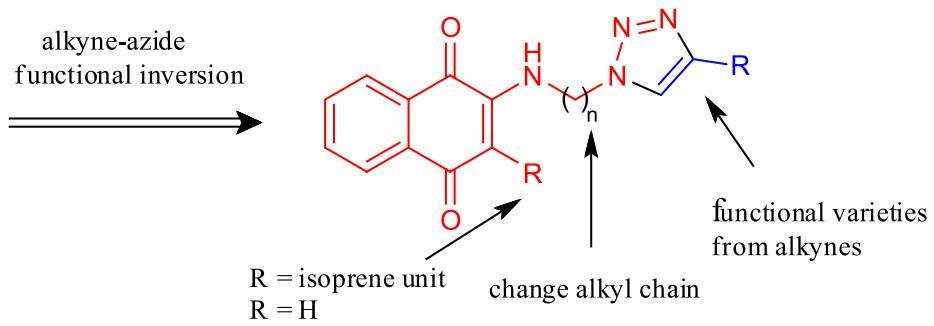

alkyne-azide functional inversion 


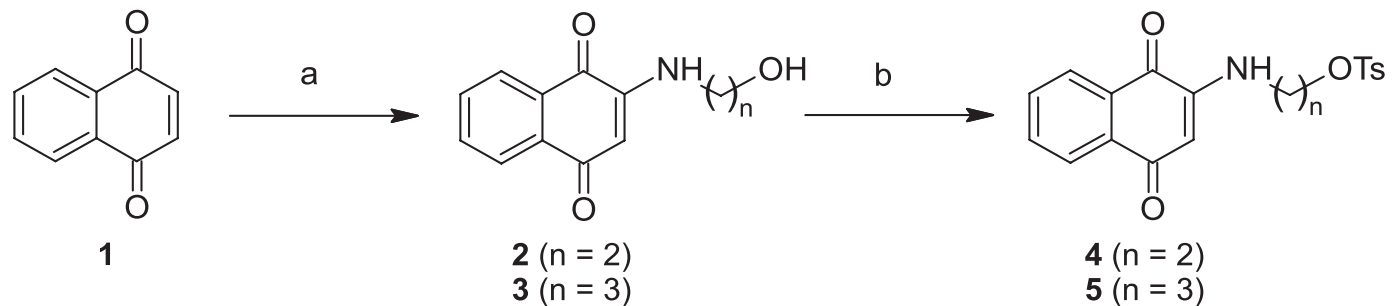<smiles>[R]c1cn(NC2=CC(=O)c3ccccc3C2=O)nn1</smiles>

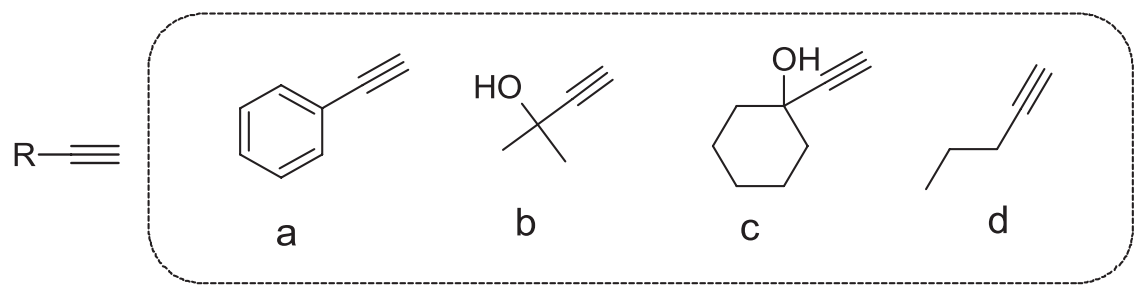

Scheme 1. Reagents and conditions: (a) ethanolamine, $\mathrm{MeCN}$, r.t., $3 \mathrm{~h}(67-73 \%)$; (b) $\mathrm{TsCl}, \mathrm{Et}_{3} \mathrm{~N} \mathrm{CH}_{2} \mathrm{Cl}_{2}$, r.t., 5 h $(68-81 \%)$; (c) $\mathrm{NaN}$, $\mathrm{DMSO}, 50{ }^{\circ} \mathrm{C}$, $10 \mathrm{~min}$; (d) $\mathrm{RC} \equiv \mathrm{CH}, \mathrm{CuI}, \mathrm{Et}_{3} \mathrm{~N}$, DMSO, r.t., 2-5 h (70-96\%).

quinones 8a-d and 9a-d starting from 1,4-NQ and amino alcohols resulted in an overall yield of roughly $40 \%$ after four steps.

The structures of compounds $(\mathbf{8 a}-\mathbf{d}, \mathbf{9 a - d})$ were assigned on the basis of their ${ }^{1} \mathrm{H}$ and ${ }^{13} \mathrm{C}$ nuclear magnetic resonance (NMR), and electrospray ionization highresolution mass spectrometry (ESI-HRMS) analysis. The hydrogen $\mathrm{H}-5^{\prime}$ in the triazolic ring appears as a singlet in the ${ }^{1} \mathrm{H}$ NMR spectral region between $\delta 7.47$ and $8.57 \mathrm{ppm}$. Naphthoquinone hydrogens $\left(\mathrm{Naph}-\mathrm{H}_{3}\right)$ absorb as a singlet at $\delta$ 5.6-5.8 ppm. The methylene hydrogens $\left(\mathrm{CH}_{2}\right)_{n}$ showed the side chain as a more displaced triplet with respect to $\mathrm{CH}_{2}$-triazol. A pseudo quartet for methylene protons in $\mathrm{NH}-\mathrm{CH}_{2}$, caused by hydrogens on $\mathrm{NH}$ and $\mathrm{CH}_{2}$, is located upfield at $\delta$ 3.6-3.7 ppm (8a-d) or $\delta$ 2.8-3.2 ppm (9a-d). The NH protons absorbed about $\delta 7.5 \mathrm{ppm}$ splitting into a broad triplet $\left(J_{v i c}\right.$ ca. $\left.5.4-6.1 \mathrm{~Hz}\right)$.

After these initial results, we envisaged the preparation of 2-amino-1,4-NQ derivatives by another synthetic route (Strategy B, cf. Scheme 2). We thought that 2-amino-alkyl(1H-1,2,3-triazol-1-yl)-1,4-naphthoquinones could be synthesized from amine-1,2,3-triazoles; the scope of these reactions is depicted in Scheme 2. To pursue the Strategy B, we started from the reaction of bromo-alkyl phthalimides 10a-c with sodium azide in DMF at $60{ }^{\circ} \mathrm{C}$ to obtain azide compounds in isolated yields of 70-93\%. Azide substrates were subjected to click protocol with phenyl acetylene to afford the 1,2,3-triazoles under ultrasound irradiation..$^{32}$ These crude materials, after ordinary filtration using silica gel, were immediately used for the next step. A mixture of methanol and hydrazine solution $\left(25 \mathrm{wt} . \%\right.$ in $\left.\mathrm{H}_{2} \mathrm{O}\right)$ was employed to furnish amino-1,2,3-triazoles 11a-c in overall good yields of $49-84 \%$ (three steps). The structures of the compounds 11a-c were determined by spectroscopy (see Experimental section). For the compounds 11b and 11c, ${ }^{1} \mathrm{H}$ NMR spectra show a different chemical shift value for the hydrogen atoms linked to nitrogen from the amine group (Figures S48 and S50). This effect could be explained by a hydrogen bond with nitrogen lone-pair electrons, as already known for 1,2,3-triazole ring. ${ }^{34}$ Finally, a facile procedure was introduced for the synthesis of compounds 2-aminoalkyl-1,2,3-triazole-1,4-NQs 8a, 9a and 12 with $83-90 \%$ of yields (Scheme 2).

The synthesis of $\mathbf{8 a}$ via Strategy A (Scheme 1) showed an overall yield of $47 \%$ (four steps). With Strategy B (Scheme 2), all individual steps shown yielded up to $90 \%$ 
Table 1. Synthesis of 1,2,3-triazoles 8a-d and 9a-d via Strategy A

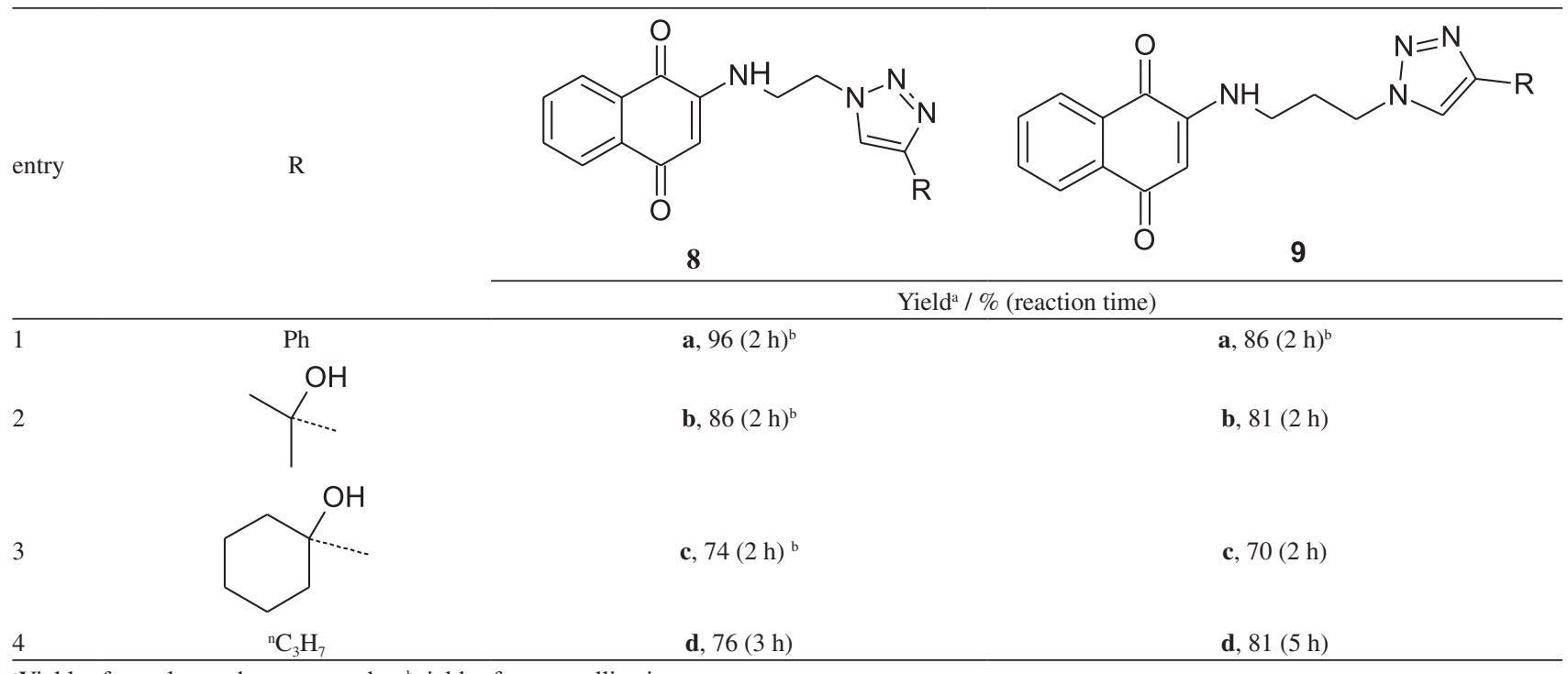

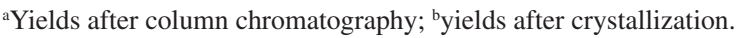
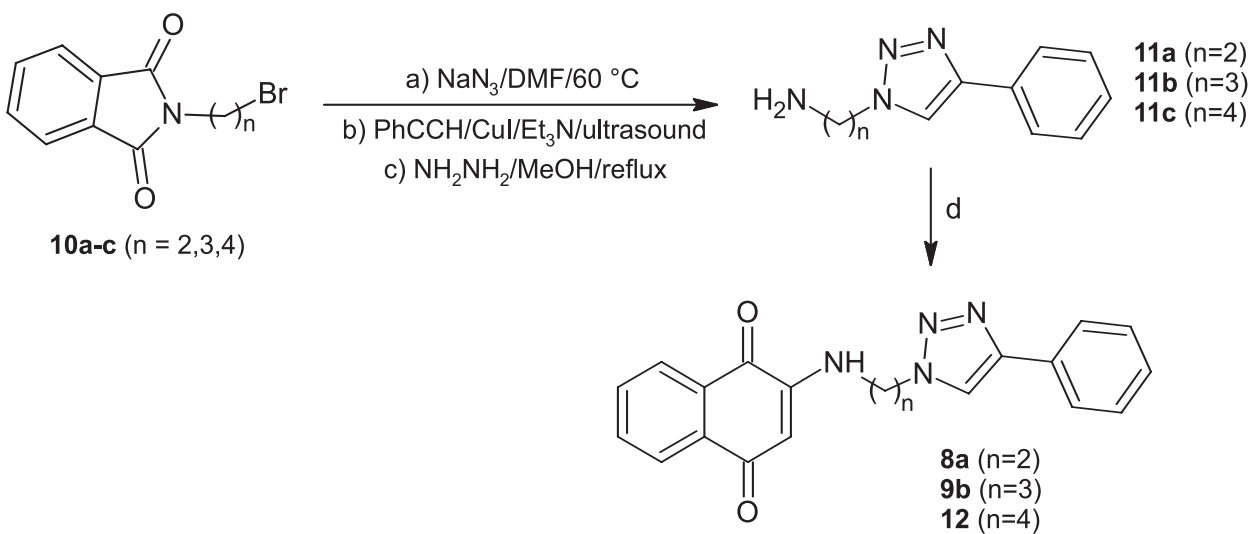

Scheme 2. Reagents and conditions: (a) $\mathrm{NaN}_{3}, \mathrm{DMF}, 60{ }^{\circ} \mathrm{C}, 24 \mathrm{~h}$; (b) $\mathrm{Ph}-\mathrm{C} \equiv \mathrm{CH}, \mathrm{CuI}, \mathrm{Et} \mathrm{N}_{3} \mathrm{~N}$, ultrasound, 30 min; (c) $\mathrm{NH}_{2} \mathrm{NH}_{2}, \mathrm{MeOH}$ reflux, $2 \mathrm{~h}$ ( $49-84 \%$ in three steps); (d) 1,4-naphthoquinone, $\mathrm{MeCN}$, r.t., $1.5 \mathrm{~h}$ (83-90\%).

and, consequently there was an overall yield of $76 \%$ (four steps). For compounds $\mathbf{9 a}$ and $\mathbf{1 2}$, the results for global yields are similar as for Strategy A $(46 \%)$, i.e., the route via Strategy B led to $45 \%$ yield after four steps.

Therefore, based on the 1,4-naphthoquinone natural scaffolds, we focused our strategies on preparing new derivatives from nor-lapachol 14 and lapachol 15 to exploring their molecular diversification based on nucleophilic displacement of correspondent methoxy-naphthoquinones $\mathbf{1 6}$ and 17 with primary amines. This type of analogous has been investigated due to the biological activity of lapachol amine derivatives. ${ }^{35}$ To the best of our knowledge, reports on these kinds of hybrids have not been published and represent new opportunities in medicinal chemistry in the design of small molecules libraries for drug discovery.

Using the adapted Kopanski et al. method, ${ }^{36}$ we prepared $\mathbf{1 4}$ from the condensation between lawsone $\mathbf{1 3}$ and isobutyraldehyde ( $92 \%$ yield). After this, we converted compounds 14 and 15 into their corresponding methylated products $\mathbf{1 6}$ and $\mathbf{1 7}$ with yields of 58 and $91 \%$, respectively (Scheme 3).

For nor-lapachol 14, Strategy A (linear synthesis) was chosen to prepare the 2-amino-1,4-NQ-1,2,3-triazoles. This choice was because of the better reactivity of nor-lapachol with amines, ${ }^{35}$ which then permitted it to be used for a linear strategy. After installation of the isoprenyl group and methylation, compound $\mathbf{1 8}$ was prepared from the reaction between amino ethanol and compound $\mathbf{1 6}$ in yields of $88 \%$. The tosylated intermediate $\mathbf{1 9}$ was prepared and purified (without characterization) and used immediately in the next step. Then, the tosylated compound $\mathbf{1 9}$ was treated with $\mathrm{NaN}_{3} / \mathrm{DMSO}$ to furnish $\mathbf{2 0}$ in $65 \%$ (two steps). The azide 
compound 20 underwent click protocol to obtain 21a-d in yields of $80-96 \%$, and an overall yield of approximately $27 \%$ from lawsone in six steps.

On the other hand, Strategy B (convergent synthesis) was employed to synthesize the 2-amino-1,4-NQs from a reaction between methylated lapachol $\mathbf{1 7}$ with aminotriazoles 11a-c. This strategy led to the amino-lapachol derivatives 22a-c in moderate to low yields, from 30 to $46 \%$; in all cases the starting materials remained unreacted. Probably a steric hindrance effect of the phenyl in C-3 position determined this behavior. In an attempt to increase the yields, the reactions were carried out under microwave irradiation; however they failed. Using this strategy, we found the global yield to be about 21\% (Scheme 3 and Table 2).

The structures of the compounds 8a-d, 9a-d and 21a-d were assigned on the basis of their ${ }^{1} \mathrm{H}$ and ${ }^{13} \mathrm{C}$ NMR spectra, elemental analyses and ESI-HRMS. A complete spectral investigation of compounds 22a-c through 1D and 2D NMR (correlation spectroscopy (COSY) and heteronuclear multiple-quantum correlation spectroscopy (HMQC)) techniques allowed us to assign its structure as 2-[(4-phenyl-1H-1,2,3-triazol-1-yl)alkyl-amino)]-3(3-methylbut-2-en-1-yl)-1,4-naphthoquinones 22a-c (see Figures in Supplementary Information). The relations between $\mathrm{NH}$, vinylic hydrogens $(H \mathrm{C}=\mathrm{C})$ and methylene protons and the methyl groups were assigned using correlated spectral data. For instance, vinylic hydrogens
( $\delta$ ca. 5 ppm) show a strong correlation in the COSY spectrum to methylene hydrogens at C-3, which appear at $\delta 47-51 \mathrm{ppm}$ according to the HMQC, as expected for lapachol derivatives. ${ }^{35,37}$

The amino-alkyl-1,2,3-triazole-1,4-naphthoquinones obtained from methylated nor-lapachol and lapachol, agreed with those currently proposed mechanisms for nucleophilic substitution reactions (Scheme 4). ${ }^{37}$ The first step involved a Michael addition reaction between 1,4-naphthoquinones and the amino compounds; a subsequent proton transfer and solvent-mediated elimination of methanol led to desired products.

\section{Conclusions}

In this work, two strategies based on click-chemistry for the synthesis of new 2-amino-alkyl-1,2,3-triazole-1,4naphthoquinones derivatives were defined. These strategies permitted us to obtain the desired products in an overall good yields from 1,4-NQ, lawsone and lapachol. These synthetic strategies may lead us to new opportunities to build smallmolecule libraries for future biological exploration.

\section{Experimental}

Air- and moisture-sensitive reactions were carried out under argon atmosphere. Reagents were purchased

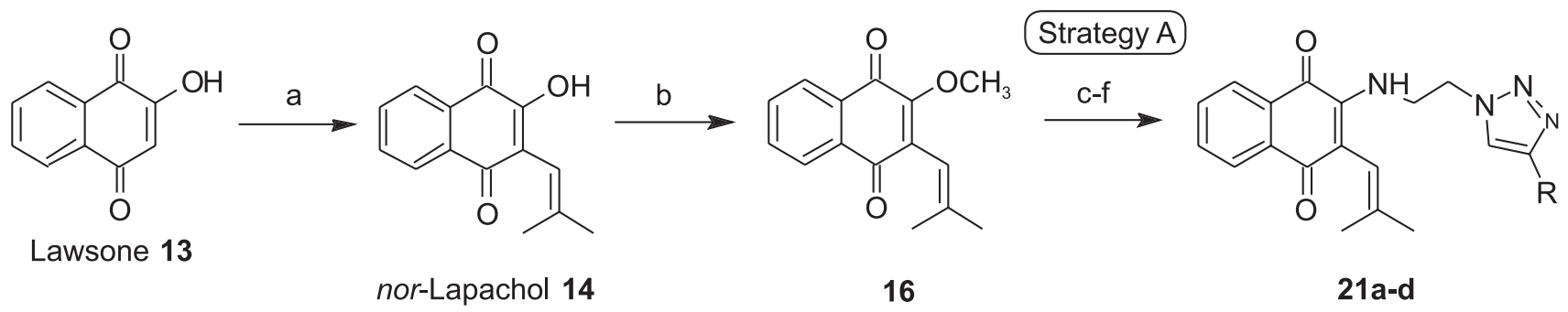

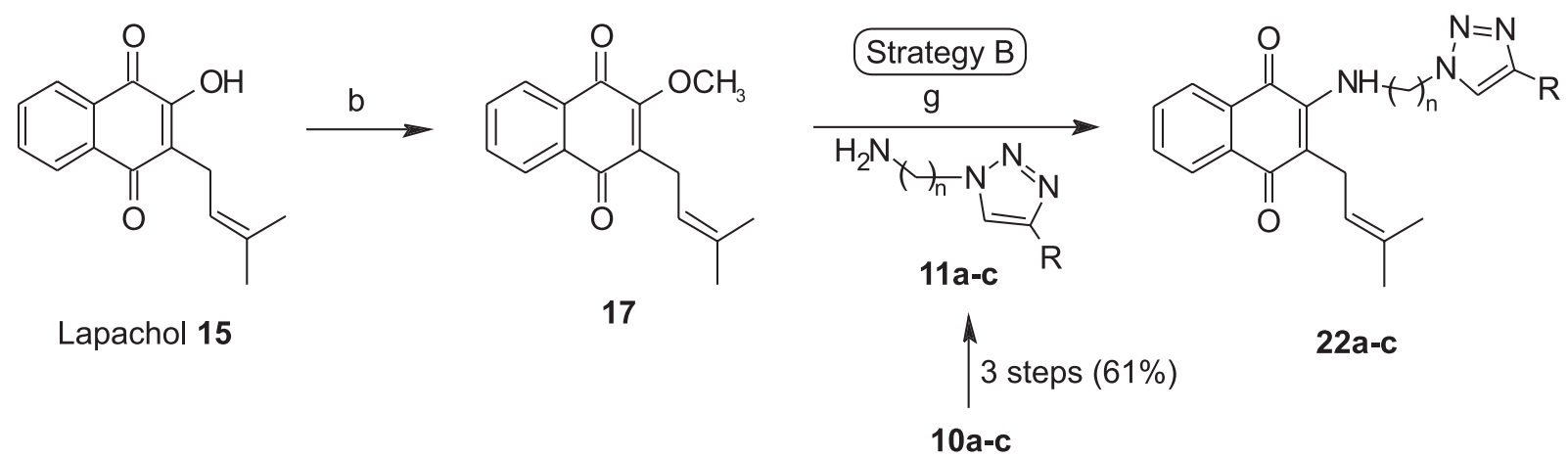

Scheme 3. Reagents and conditions: (a) isobutyl aldehyde, $\beta$-alanine, $\mathrm{AcOH}$, toluene, $120{ }^{\circ} \mathrm{C}, \mathbf{1 4}(92 \%)$; (b) $\mathrm{Me}_{2} \mathrm{SO}_{4}, \mathrm{~K}_{2} \mathrm{CO}_{3}$, acetone, r.t., 3 h, 16 (58\%), 17 (91\%); (c) ethanolamine, $\mathrm{MeOH}$, r.t., 24 h, 18 (88\%); (d) TsCl, $\mathrm{Et}_{3} \mathrm{~N}, \mathrm{CH}_{2} \mathrm{Cl}_{2}$, r.t., 3 h, 19; (e) $\mathrm{NaN}_{3}$, DMSO, r.t., 8 h, 20 (65\%, two steps); (f) RC $\equiv \mathrm{CH}$, CuI, $\mathrm{Et}_{3} \mathrm{~N}, \mathrm{DMSO}$, r.t., 2 h, 21a-d (80-96\%); (g) amino-triazole, $\mathrm{MeOH}$, r.t., 24 h, 22a-c (30-46\%). 
Table 2. Synthesis of compounds 21a-d and 22a-c

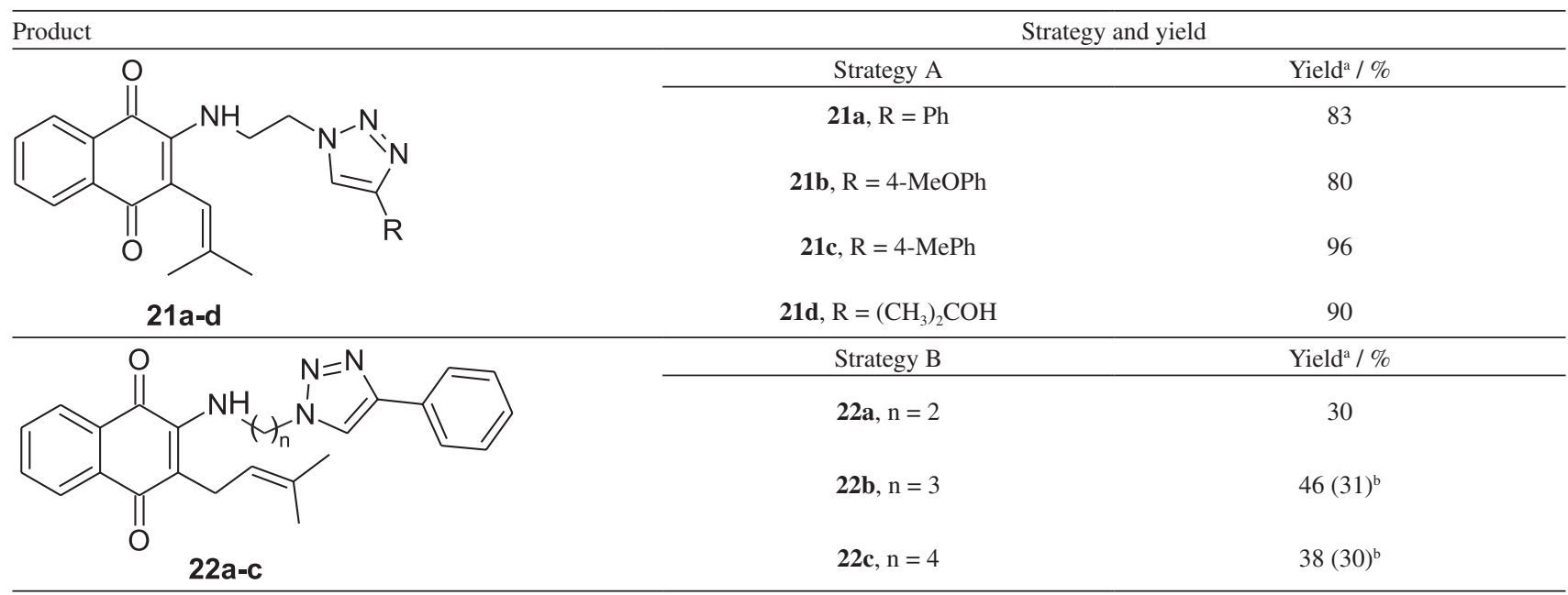

${ }^{a}$ Yields after column chromatography; ${ }^{b}$ yields in brackets are where microwave irradiation was applied.

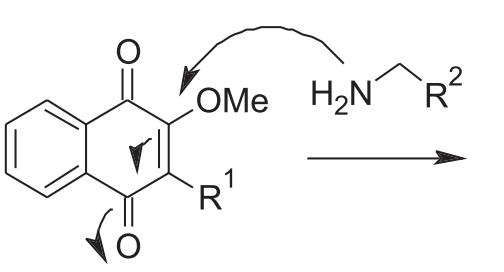

$16 R^{1}$ :

$17, \mathrm{R}^{1}$<smiles>[R]C[NH2+]C1(OC)C(=O)c2ccccc2C([O-])=C1[R]</smiles>

Proton transfer

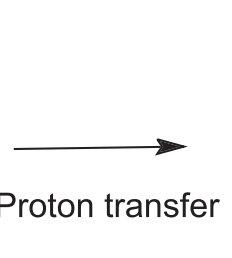

solvent-mediated<smiles>[R]CNNC1(OC)C([R])=C(O)C(C)=C1C(=O)NCOC</smiles><smiles>[R]CNC1=C([R])C(=O)c2ccccc2C1=O</smiles>

$\mathrm{R}^{1}$ :<smiles>CC=C(C)CCC=C(C)C</smiles>

$\mathrm{R}^{2}$ : $\mathrm{CH}_{2} \mathrm{OH}$; alkyl-1,2,3-triazole

Scheme 4. Mechanism for amino-1,4-NQs from methylated lapachol and nor-lapachol.

from Acros or Sigma-Aldrich and used without further purification. Reactions were monitored by TLC analysis on precoated silica gel plates (Merck, Kieselgel 60F254) and compounds were visualized with UV light. Column chromatography was performed on silica gel SI 60 (70-230 mesh, Merck). Melting points were measured in open capillary tubes in a PFM II BioSan apparatus and are uncorrected. Elemental analyses were carried out in an EA1110 CHNS-O analyzer. Microwave reactions were conducted in a focused microwave (FMW) power delivery system, using a CEM Discover Synthesis (Model 908005 , 0-300 W, $2455 \mathrm{MHz}$, CEM Corporation). Power applied for the synthesis was $100 \mathrm{~W}$ and procedure temperature was $75{ }^{\circ} \mathrm{C}$. The reactions were performed in sealed glass vessels (capacity $10 \mathrm{~mL}$ ). The infrared spectra were recorded on an IFS66 Bruker spectrophotometer using $\mathrm{KBr}$ discs. HRMS analyses were performed on a LC-MS/ESI(-)TOF spectrometer (Model Xevo G2-XS QTof, Waters). NMR ( ${ }^{1} \mathrm{H}$ at $400 \mathrm{MHz}$ and ${ }^{13} \mathrm{C}$ at $\left.100 \mathrm{MHz}\right)$ spectra were recorded on a Varian Unity Plus-400 spectrometer, using $\mathrm{CDCl}_{3}$ or DMSO- $d_{6}$ as solvents, and calibrated for the solvent signal. Chemical shifts are expressed in parts per million (ppm) and coupling constants are given in Hz. Assignments are based on COSY and heteronuclear single quantum coherence (HSQC) experiments. 


\section{Supplementary Information}

Supplementary information (spectra for IR, ${ }^{1} \mathrm{H}$ and ${ }^{13} \mathrm{C}$ NMR and HRMS of the synthesized compounds) is available free of charge at http://jbcs.sbq.org.br as PDF file.

\section{Acknowledgments}

The authors are grateful to CNPq (448082/2014-4), FACEPE-PRONEM (APQ 0741-1.06/14) and CAPES for financial support and fellowships. Our thanks are also extended to Analytical Center DQF-UFPE and CENAPESQ-UFRPE.

\section{References}

1. Hudlický, T.; Reed, J. W.; The Way of Synthesis. Evolution of Design and Methods for Natural Products; Wiley-VCH Verlag GmbH \& Co. KGaA: Weinheim, 2007.

2. Rostovtsev, V. V.; Green, L. G.; Fokin, V. V.; Sharpless, K. B.; Angew. Chem., Int. Ed. 2002, 41, 2596.

3. Tornøe, C. W.; Christensen, C.; Meldal, M. P.; J. Org. Chem. 2002, 67, 3057.

4. Jlaila, I.; Beauvineau, C.; Beauvière, S.; Önen, E.; Aufort, M.; Beauvineau, A.; Khaba, E.; Herscovici, J.; Meganem, F.; Girard, C.; Molecules 2010, 15, 3087.

5. Goyard, D.; Docsa, T.; Gergely, P.; Praly, J.-P.; Vidal, S.; Carbohydr. Res. 2015, 402, 245.

6. Yoshida, S.; Nonaka, T.; Morita, T.; Hosoya, T.; Org. Biomol. Chem. 2014, 12, 7489.

7. Haldón, E.; Álvarez, E.; Nicasio, C.; Pérez, P. J.; Chem. Commun. 2014, 50, 8978.

8. Kommgalla, Y.; Cornea, S.; Riehle, R.; Torchilin, V.; Degterev, A.; Ramana, C. V.; Med. Chem. Commun. 2014, 5, 1359.

9. Günther, K. U.; Ziegler, T.; Synthesis 2014, 2362.

10. Dedola, S.; Hughes, D. L.; Nepogodiev, S. A.; Rejzek, M.; Field, R. A.; Carbohydr. Res. 2010, 345, 1123.

11. Yoshida, S.; Nonaka, T.; Morita, T.; Hosoya, T.; Org. Biomol. Chem. 2014, 12, 7489.

12. Kolb, H. C.; Sharpless, K. B.; Drug Discovery Today 2003, 8, 1128.

13. Thirumurugan, P.; Matosiuk, D.; Jozwiak, K.; Chem. Rev. 2013 , 113, 4905 .

14. Kumar, K. K.; Seenivasan, S. P.; Kumar, V.; Das, T. M.; Carbohydr. Res. 2011, 346, 2084.

15. Xia, Y.; Li, W.; Qu, F.; Fan, Z.; Liu, X.; Berro, C.; Rauzy, E.; Peng, L.; Org. Biomol. Chem. 2007, 5, 1695.

16. Wellington, K. W.; RSC Adv. 2015, 5, 20309.

17. da Cruz, E. H. G.; Hussene, C. M. B.; Dias, G. G.; Diogo, E. B. T.; de Melo, I. M. M.; Rodrigues, B. L.; da Silva, M. G.; Valença, W. O.; Camara, C. A.; de Oliveira, R. N.; de Paiva, Y.
G.; Goulart, M. O. F.; Cavalcanti, B. C.; Pessoa, C.; da Silva Jr., E. N.; Bioorg. Med. Chem. 2014, 22, 1608.

18. Delarmelina, M.; Daltoé, R. D.; Cerri, M. F.; Madeira, K. P.; Rangel, L. B. A.; Lacerda Jr., V.; Romão, W.; Tarantod, A. G.; Greco, S. J.; J. Braz. Chem. Soc. 2015, 26, 1804.

19. Sangshetti, J. N.; Nagawade, R. R.; Shinde, D. B.; Bioorg. Med. Chem. Lett. 2009, 19, 3564.

20. Xu, W. L.; Li, Y. Z.; Zhang, Q. S.; Zhu, H. S.; Synthesis 2005 , 442.

21. Agalave, S. G.; Maujan, S. R.; Pore, V. S.; Chem. - Asian J. 2011, 6, 2696.

22. Diogo, E. B. T.; Dias, G. G.; Rodrigues, B. L.; Guimarães, T. T.; Valença, W. O.; Camara, C. A.; de Oliveira, R. N.; da Silva, M. G.; Ferreira, V. F.; Paiva, Y. G.; Goulard, M. O. F.; MennaBarreto, R. F. S.; Castro, S. L.; da Silva Jr., E. N.; Bioorg. Med. Chem. 2013, 21, 6337.

23. Silva, A. O.; Lopes, R. S.; de Lima, R. V.; Tozatti, C. S. S.; Marques, M. R.; Albuquerque, S.; Beatriz, A.; de Lima, D. P.; Eur. J. Med. Chem. 2013, 60, 51.

24. Naujorks, A. A. S.; da Silva, A. O.; Lopes, R. S.; Albuquerque, S.; Beatriz, A.; Marquesd, M. R.; de Lima, D. P.; Org. Biomol. Chem. 2015, 13, 428.

25. da Silva Jr., E. N.; Menna-Barreto, R. F. S.; Pinto, M. C. F. R.; Silva, R. S. F.; Teixeira, D. V.; de Souza, M. C. B. V.; de Simone, C. A.; de Castro, S. L.; Ferreira, V. F.; Pinto, A. V.; Eur. J. Med. Chem. 2008, 43, 1774.

26. Castro, S. L.; Emery, F. S.; da Silva Jr., E. N.; Eur. J. Med. Chem. 2013, 69, 678.

27. Jardim, G. A. M.; Reis, W. J.; Ribeiro, M. F.; Ottoni, F. M.; Alves, R. J.; Silva, T. L.; Goulart, M. O. F.; Braga, A. L.; Menna-Barreto, R. F. S.; Salomão, K.; Castro, S.L.; da Silva Jr., E. N.; RSC Adv. 2015, 5, 78047.

28. Lin, L.; Shen, Q.; Chen, G.-R.; Xie, J.; Bioorg. Med. Chem. 2008, 16, 9757; Bala, B. D.; Muthusaravanan, S.; Choon, T. S.; Ali, M. A.; Perumal, S.; Eur. J. Med. Chem. 2014, 85, 737.

29. Nascimento, W. S.; Camara, C. A.; de Oliveira, R. N.; Synthesis 2011, 20, 3220 .

30. Coulidiati, T. H.; Dantas, B. B.; Faheina-Martins, G. V.; Gonçalves, J. C. R.; Nascimento, W. S.; Oliveira, R. N.; Camara, C. A.; Oliveira, E. J.; Lara, A.; Gomes, E. R.; Araújo, D. A. M.; J. Pharm. Pharmacol. 2015, 67, 1682.

31. Guimarães, T. T.; Pinto, M. C. F. R.; Lanza, J. S.; Melo, M. N.; do Monte-Neto, R. L.; de Melo, I. M. M.; Diogo, E. B. T.; Ferreira, V. F.; Camara, C. A.; Valença, W. O.; de Oliveira, R. N.; Frézard, F.; da Silva Júnior, E. N.; Eur. J. Med. Chem. 2013, 63, 523.

32. da Silva, M. T.; de Oliveira, R. N.; Valença, W. O.; Barbosa, F. C. G.; da Silva, M. G.; Camara, C. A.; J. Braz. Chem. Soc. 2012, 23, 1839.

33. MacGregor, K. A.; Abdel-Hamid, M. K.; Odell, L. R.; Chau, N.; Whiting, A.; Robinson, P. J.; McCluskey, A.; Eur. J. Med. Chem. 2014, 85, 191. 
34. Yan, W.; Ye, X.; Akhmedov, N. G.; Petersen, J. L.; Shi, X.; Org. Lett. 2012, 14, 2358.

35. Barbosa, T. P.; Camara, C. A.; Silva, T. M. S.; Martins, R. M.; Pinto, A. C.; Vargas, M. D.; Bioorg. Med. Chem. 2005, 13, 6464.

36. Kopanski, L.; Karbach, D.; Selbitschka, G.; Steglich, W.; Liebigs Ann. Chem. 1987, 793.
37. Camara, C. A.; Pinto, A. C.; Rosa, M. A.; Vargas, M. D.; Tetrahedron 2001, 57, 9569 and cited references.

Submitted: May 5, 2016

Published online: July 13, 2016 